\title{
Cartas a Juan Antonio Cabezas: un epistolario inédito
}

\section{Letters to Juan Antonio Cabezas: an Unpublished Collection}

\author{
Pablo Núñez Díaz \\ UNED Asturias \\ ndpablo@gijon.uned.es \\ ORCID iD: https://orcid.org/0000-0002-0067-0595
}

\begin{abstract}
RESUMEN
El objetivo de este artículo es ofrecer, por primera vez, la edición de las catorce cartas de escritores que se conservan en el archivo epistolar del periodista y escritor asturiano Juan Antonio Cabezas, inéditas hasta la fecha, y profundizar en el contenido de las mismas que pueda aportar luz sobre la historia de la literatura de su tiempo. Las misivas, fechadas entre 1957 y 1990, pertenecen a Ramón Gómez de la Serna, Antonio Ortega, Mariano Sánchez Roca, Dionisio Gamallo, José María Pemán, José María de Cossío, Guillermo de Torre, Luis Amado-Blanco, Manuel Fernández Avello, Jorge Guillén, Dolores Medio, Manuel Pilares y Natalia Figueroa (los nombres se citan siguiendo el orden cronológico de las cartas). Los documentos contienen datos de interés sobre la guerra civil española, el ambiente literario durante el franquismo, o los recuerdos y los proyectos tanto de los emisarios como del propio Juan Antonio Cabezas.
\end{abstract}

Palabras Clave: Juan Antonio Cabezas; cartas; epistolario; guerra civil española; $A B C$; Clarín.

\section{ABSTRACT}

The aim of this paper is to offer, for the first time, the edition of fourteen writers' letters that remain in the epistolary file of the Asturian journalist and writer Juan Antonio Cabezas, unpublished until now, and to delve into the content of these documents that could contribute to illuminating the history of the literature at the time. The missives, dated between 1957 and 1990, belong to Ramón Gómez de la Serna, Antonio Ortega, Mariano Sánchez Roca, Dionisio Gamallo, José María Pemán, Jose María de Cossío, Guillermo de Torre, Luis Amado-Blanco, Manuel Fernandez Avello, Jorge Guillén, Dolores Medio, Manuel Pilares and Natalia Figueroa (the names are mentioned following the chronological order of the letters). The documents contain information of interest on the Spanish Civil War, the literary environment during the Franco's regime, or the recollections and the projects of both of the emissaries and Juan Antonio Cabezas himself.

Key words: Juan Antonio Cabezas; Letters; Epistolary file; Spanish Civil War; $A B C$; Clarín. 
Juan Antonio Cabezas (Peruyes, Margolles, Cangas de Onís, 1900 - Madrid, 1993) dedicó su vida profesional al periodismo, desde finales de la década de 1920 hasta 1990. Inició su carrera como redactor de El Carbayón, periódico que llegó a dirigir, fue colaborador de los madrileños El Sol y La Voz, y actuó en la primera línea informativa en la Asturias de la II República y de la guerra civil -en 1936 y 1937-, como redactor jefe del diario socialista Avance. Después de varios años prisionero, y tras experiencias como, por ejemplo, la de redactor del Diario de Tánger, ejerció como periodista en $A B C$ durante cerca de un cuarto de siglo. Pero la literatura también fue esencial en su carrera, como autor de la primera biografía de Leopoldo Alas «Clarín»-Clarín, el provinciano universal (1936)-; como biógrafo de Concepción Arenal (Cabezas 1942), de Rubén Darío (Cabezas 1944) -libro con el que obtuvo el Premio Fastenrath de la Real Academia Española- o de Miguel de Cervantes (Cabezas 1962), entre otros; y como autor de ocho novelas, desde Señorita 0-3 (Cabezas 1932) hasta Nandú (Cabezas 1990).

Una carrera dedicada al ejercicio de las letras y del periodismo difícilmente podía no ser permeable a la correspondencia con otros escritores. El objetivo de este artículo es ofrecer el resultado del estudio de su epistolario, hasta ahora inédito, que está integrado por cartas de Ramón Gómez de la Serna, Antonio Ortega, Mariano Sánchez Roca, Dionisio Gamallo, José María Pemán, José María de Cossío, Guillermo de Torre, Luis Amado-Blanco, Manuel Fernández Avello, Jorge Guillén, Dolores Medio, Manuel Pilares y Natalia Figueroa -al citarlos, sigo el orden cronológico de las misivas-. Se trata de cartas recibidas entre 1957 y 1990 . No se conservan cartas anteriores, que sin duda habrían tenido un interés histórico considerable, especialmente las que pudo haber recibido durante la II República y la guerra civil. Acaso estas fueron destruidas por miedo a que sirvieran como prueba de compromiso político republicano, no tanto del propio Cabezas, pues dicho compromiso era evidente al formar parte de Avance, como de los emisarios, a quienes habría querido proteger.

Pero las cartas que presento en este trabajo también contienen datos de interés en lo que respecta a la guerra civil española, el ambiente literario durante el franquismo, los recuerdos, las inquietudes y los proyectos tanto de los emisarios como del propio Juan Antonio Cabezas. En esta breve introducción y en las notas a pie de página trataré de facilitar la comprensión de las mismas en la medida de lo posible.

Ramón Gómez de la Serna, en su carta, agradece a Cabezas la publicación de un artículo ${ }^{1}$ sobre su «vida personal y literaria», según él mismo indica. El

${ }^{1}$ En aquel entonces, Juan Antonio Cabezas, además de publicar en $A B C$-donde no he localizado el artículo en cuestión-, lo hacía también en el España de Tánger, en Gaceta Ilustrada, en la «Tribuna Literaria» de la revista Medicamenta, en la revista Mundo Hispánico, y escribía dos colaboraciones mensuales que la American Literary Agency de Nueva 
documento está firmado en Buenos Aires, en el año 1957, y en él Gómez de la Serna afirma haber entregado a Maruja Mallo «su correspondiente recorte». «iQue vivamos muchos años, que articuleemos mucho y que sea por lo menos fértiles en dólares nuestra vieja e incesante labor!», escribe el creador de las greguerías, cuyos ingresos se sustentaban entonces, en buena medida, en las colaboraciones periodísticas. Así lo aseguraba, un año antes, en una entrevista en $A B C$ con J. E. Casariego: «Soy pobre, y a mis años y con mi obra hecha tengo que remar a diario como un galeote para poder subsistir. Tengo que escribir 21 artículos al mes, entre mis colaboraciones de España e Hispanoamérica...» (Casariego 1956, 9).

Por su parte, Dionisio Gamallo, en su misiva, de 1963, da noticia a Cabezas de que ha comprado el epistolario de Clarín por 30.000 pesetas, que utilizará las cartas «literariamente», que percibirán derechos los herederos en caso de publicarse algún día en tomos, $\mathrm{y}$, si se organiza un museo dedicado a la obra del autor de La Regenta, aportará el epistolario,

con la única exigencia por mi parte de que no se dispersen, se mutilen, o parcialmente destruyan, porque cartas hay que determinadas gentes desearían no se hubieran escrito nunca, ya que sirven para comprobar que el tradicional sectarismo español ha ido en muchos aspectos 'in crescendo' y que altos espíritus como Pereda, M. Pelayo, Maura, etcétera, trataron a Alas con bastante más generosidad y justicia que carcas de tercera y cuarta categoría de ahora.

Las 715 cartas estaban en posesión de María Cuervo, viuda de Adolfo Alas Argüelles, segundo hijo de Leopoldo Alas Clarín². Hasta la fecha de la compra, se habían publicado Epistolario a Clarín, con cartas de Marcelino Menéndez Pelayo, Miguel de Unamuno y Armando Palacio Valdés, con prólogo y notas de Adolfo Alas (Menéndez Pelayo, Unamuno y Palacio Valdés 1941) y el epistolario entre Clarín y Menéndez Pelayo, con prólogo de Gregorio Marañón y notas de Adolfo Alas (Menéndez Pelayo y Alas 1943). Gamallo publicó años más tarde dos cartas de Campoamor a Clarín (Gamallo Fierros 1985), así como «La Regenta, a través de cartas inéditas de la Pardo Bazán a Clarín» (Gamallo Fierros 1987$)^{3}$.

York distribuía a importantes periódicos de Hispanoamérica, según me indica Julia Cabezas García (2019a).

${ }^{2}$ La disparidad de criterios entre los descendientes de Clarín y entre Gamallo Fierros (y posteriormente los descendientes de este) sobre la legitimidad de la posesión del epistolario apareció en la prensa: vid., María Paz Alas, «El epistolario de "Clarín"», La Nueva España, 19 de mayo de 1963, p. 6; «Los herederos de Clarín dicen que sus cartas se adquirieron de forma irregular», La Voz de Asturias, 24 de mayo de 2001, p. 36; María Gamallo Fierros, «En defensa de Dionisio Gamallo», La Voz de Asturias, 13 de junio de 2001, p. 6. El archivo epistolar de Clarín lo tutela en la actualidad la familia Deaño Gamallo.

3 Desde entonces, han visto la luz cartas a Clarín de Manuel del Palacio (Botrel 1997), de Benito Pérez Galdós (Rubio Jiménez y Smith 2005-2006 y Rubio Jiménez 2009), y el 
La carta de Dionisio Gamallo a Cabezas adquiere todo el sentido si tenemos presente el papel de este último como primer biógrafo del autor de La Regen$t a$, en una España donde la figura de Clarín seguía siendo difícil de aceptar para determinados sectores. Cabezas ya había dejado constancia de su pasión por Clarín años antes de publicar su biografía. Elvira Bobo Cabezas $(2010,8)$ da noticia de un reportaje que el periodista firmó en El Carbayón, en 1927, con motivo de una visita a la Universidad de Oviedo, en el que escribe lo siguiente en referencia a la cátedra de Clarín: «Lo grande no era la tribuna, no era la cátedra, no era ni siquiera la figura de don Leopoldo. Lo grande era su pensamiento, y de ese no quedó huella en las paredes, ni nos lo pueden evocar las lápidas, sólo podremos encontrar fragmentos de él, abriendo sus libros» (citado en Bobo Cabezas 2010, 8).

Respecto a la carta de Luis Amado-Blanco, este agradece a Cabezas que en su correspondencia se hubiera referido a la «intemporalidad» de la novela corta Esteta Rodríguez, cuando él mismo empezaba a dudar de ella, a los diez años de escribirla. Esta obra forma parte del libro Un pueblo y cuatro agonías (Amado-Blanco 2003). La carta también hace referencia a Un pueblo y dos agonías (Amado-Blanco 1955). En ambos títulos, se observa el término utilizado por Miguel de Unamuno para referirse a las novelas cortas. El libro está compuesto por la introducción El pueblo y por las novelas El gato y Mi tío Romualdo. Posteriormente, Amado-Blanco añadió Esteta Rodríguez y Mi tío Romualdo, por lo que el título pasó a ser Un pueblo y cuatro agonías, que no se publicó hasta 2003, con motivo del centenario del nacimiento del autor. La intención de Amado-Blanco de llevar a cabo este proyecto se recoge en una carta que dirigió a José Antonio Mases desde Roma el 26 de febrero de 1970 (vid. González Martell 2003, 20-21). La carta a Juan Antonio Cabezas aquí presentada es un testimonio ligeramente anterior, que viene a confirmar la misma idea.

El contacto epistolar entre Jorge Guillén y Juan Antonio Cabezas aquí recogido se produce a raíz de la obra Asturias: catorce meses de guerra civil (Cabezas 1975), que Guillén leyó con interés, lo que le llevó a dirigirse al editor Gregorio del Toro solicitándole la dirección personal de Cabezas. Esta

corpus que desde 2009 han venido publicando Jesús Rubio Jiménez y Antonio Deaño Gamallo: de Francisco Giner de los Ríos (Rubio Jiménez y Deaño Gamallo 2009), Rafael Altamira y José Martínez Ruiz «Azorín» (Rubio Jiménez y Deaño Gamallo 2011), José María de Pereda (Rubio Jiménez y Deaño Gamallo 2012a), Gaspar Núñez de Arce (Rubio Jiménez y Deaño Gamallo 2012b), Emilio Castelar (Rubio Jiménez y Deaño Gamallo 2012c), Rubén Darío (Rubio Jiménez 2013), Ramón de Campoamor (Rubio Jiménez y Deaño Gamallo 2013), Enrique Gómez Carrillo (Rubio Jiménez y Deaño Gamallo 2014a), Adolfo Posada (Rubio Jiménez y Deaño Gamallo 2014b), de Salvador Rueda y, de nuevo, Rubén Darío (Rubio Jiménez y Deaño Gamallo 2014c), Juan Valera (Rubio Jiménez y Deaño Gamallo 2015) y José Fernández Quevedo, Tomás Tuero y Pío Rubín (Rubio Jiménez y Deaño Gamallo 2018). 
carta de Guillén, que se conserva en el archivo de la familia Cabezas, está fechada en Cambridge (Massachusetts) el 30 de julio de 1976, y en ella califica el libro de «magnífico». En la primera de sus cartas a Cabezas, de 18 de noviembre del mismo año, Guillén ensalza el mencionado libro y le anima a escribir «su relato completo de toda aquella historia». Guillén hace referencia a M. ${ }^{a}$ Cristina Alas Rodríguez (1925-2010), nieta de Clarín e hija de Leopoldo Alas Argüelles (1883-1937), el rector de la Universidad de Oviedo que fue fusilado por el ejército nacional en febrero de 1937. Su ejecución, que supuso una gran conmoción a escala internacional, aparece relatada en el mencionado libro de Cabezas (1975, 99-102), con quien el rector tenía amistad. También cuenta el periodista su conversación con Alas Argüelles el 19 de julio de 1936 -unas horas antes de que el rector fuera detenido-, con la incertidumbre de si el coronel Aranda se uniría al alzamiento nacional, coincidiendo ambos en que sí (1975, 15-17). Al dar noticia en Avance del trágico suceso, escribe Cabezas (1975, 101-102):

El rector de la Universidad ovetense, Leopoldo Alas, era el continuador de una tradición asturiana de cultivadores de la cultura liberal y humanística, que desde el Renacimiento produjo en nuestro suelo magníficas individualidades, especialmente en la llamada Ilustración Asturiana del siglo XVIII, desde Jovellanos, Campomanes y Flórez Estrada.

Jorge Guillén conoció a Leopoldo Alas Argüelles en el curso 1913-1914 en Halle (Alemania), donde este último preparaba su doctorado en Derecho. Como muestra de su aprecio, Guillén dedica a su memoria el libro Guirnalda civil (1970), con la dura referencia a que fue «legalmente asesinado» (Guillén 1970, 9). El autor de Cántico pregunta a Cabezas por los pintores Javier y Antonio Bueno Rosiasky, para confirmar que eran primos de Javier Bueno y Bueno (1891-1939), el director del diario Avance entre 1933 y 1937, detenido en octubre de 1934 por inducir a la Revolución, y ejecutado en prisión en 1939. Los Bueno Rosiasky eran además hijos del también periodista Javier Bueno García. Vivían en Florencia y fueron los artistas elegidos por Pío XII para realizar su primer retrato como papa.

La segunda carta, de mayo de 1977, está escrita desde Florencia, y en ella Guillén recuerda un congreso en el que coincidió con Cabezas en Puerto Rico -posiblemente se refiera a un congreso sobre lexicografía que se desarrolló hacia 1968- y le pide la fotocopia de un artículo de Francisco Garfias en $A B C$ sobre Juan Ramón Jiménez y Antonio Machado. Menciona, además, sus planes de seguir en Italia hasta finales de junio.

En su carta, de 1958, Antonio Ortega, entonces todavía director de la publicación periódica Carteles en Cuba, antes de su exilio a Venezuela por el devenir de la dictadura de Fidel Castro, expresa su cariño a Cabezas y dice leerle con admiración. Sin embargo, el motivo principal de la misiva es presentarle a un amigo, colaborador de Carteles, Mario Díaz Aguirre, que portaría 
la carta, y a quien Ortega define como «un gran escritor y periodista». Díaz Aguirre llevaba consigo un libro inédito, Cromos de ayer, colaboraciones que en su mayor parte ya habían visto la luz en la revista, y tenía interés en publicarlo en España. Ortega le pide a Cabezas que le presente

a los buenos amigos que por ahí me queden, que le facilites las gestiones que tendrá que hacer para sacar su libro... Deseo también que le enseñes la otra cara de España que está por debajo de los «luceros», los «yugos» y la «vocación de imperio» actuales. Esa otra cara de España que es preciso mostrar a los americanos para que nos perdonen el haber descubierto América y se descubran a sí mismos. Tú, asturiano de mente clara que has vivido en América, sé que aceptarás mi encargo. Puedo decirte también que todo lo que hagas por Mario Díaz Aguirre, se lo merece.

La carta que el abogado Mariano Sánchez Roca envía a Cabezas en diciembre de 1961 muestra de forma nítida dos realidades del mundo intelectual y literario: la primera de ellas, propia de su tiempo, es el exilio, motivado primero por el franquismo y, posteriormente, por el castrismo; la segunda realidad es la dificultad para publicar y la habilidad social con la que se intenta superar dicha adversidad: una vez alcanzado el objetivo de publicar su libro anticomunista en Francia, Sánchez Roca busca el favor de Cabezas para que le ayude a conseguirlo en España, sin descartar incluso fundar una imprenta en nuestro país y publicar la obra él mismo.

José María Pemán, en abril de 1967, felicita a Cabezas por su libro Cervantes. Del mito al hombre (Cabezas 1967), que encuentra «lleno de sugestión y novedades». Ambos escritores eran nombres importantes de $A B C$, Cabezas como redactor en plantilla y Pemán como articulista.

José María de Cossío responde a Cabezas desde la Casona de Tudanca, en julio de 1967. El periodista asturiano le había preguntado por su contacto con Rubén Darío, cuando el autor de Cantos de vida y esperanza estuvo en Madrid a su paso hacia Valldemossa -recuérdese que Cabezas publicó una biografía de Rubén en 1944-. Cossío afirma que nada hubo de interés en ese «fugaz contacto». Asimismo, Cossío le invita a visitar la Casona en un próximo viaje que Cabezas planea a la montaña, y afirma leer su colaboración diaria en $A B C$ con el mayor interés.

Si bien el contenido de la carta del periodista ovetense Manuel Fernández Avello no resulta del todo claro (¿qué libro le devuelve? ¿de qué cuestiones hablaron en persona?), lo cierto es que sí evidencia la relación cercana que había entre ellos, así como el hecho de que Fernández Avello departió con Cabezas sobre un proyecto editorial que se realizaría al año siguiente: la biografía de José Tomás Rodríguez y de la Iglesia Bobes (1782-1814), marino ovetense que fue capitán del ejército español en la guerra de la secesión de Venezuela, donde murió herido en combate, que Fernández Avello dio a la 
imprenta al año siguiente bajo el título Bobes. Mariscal asturiano para la historia (Fernández Avello 1974).

La carta de Guillermo de Torre, de julio de 1968, tiene como fin agradecerle su mención en la «Tertulia literaria», una sección que Cabezas firmaba en el suplemento semanal «Mirador Literario», que en esa época $A B C$ publicaba los jueves. El artículo mencionado apareció el 4 de julio de 1968, y en él Juan Antonio Cabezas anuncia la cercana publicación del libro de Guillermo de Torre El espejo y el camino (Editorial Prensa Española, Madrid, 1968). Torre le pregunta si sigue yendo al Café Lion, donde le había encontrado la última vez. Este histórico establecimiento, ubicado en la madrileña calle de Alcalá, muy cerca de Cibeles, era lugar de encuentro para Cabezas con Fernando Vela, Gerardo Diego, José García Nieto, Ramón Ledesma Miranda, Juan Pérez Creus, Pedro Mourlane Michelena, etcétera. No debe confundirse con el Café Lion d'Or, fundado por la misma familia, y también en la calle de Alcalá, pero cerca de la Puerta del Sol, que fue sede de tertulias como la que encabezaba José M. a de Cossío, inmortalizada por Antonio Díaz Cañabate en Historia de una tertulia (Díaz Cañabate 1978) -la familia de Juan Antonio Cabezas conserva testimonio gráfico de que el periodista también llegó a acudir al Lion d'Or (Cabezas García, 2018a)-.

La carta de la novelista Dolores Medio, de 14 de abril de 1980, muestra su amistad con Juan Antonio Cabezas, que incluía la lectura mutua de las nuevas obras publicadas. La novelista señala que en sus memorias le cita «más que a ninguno de los historiadores de mi época, porque, como confieso, eres a mi juicio el mejor informado». Dichas memorias vieron la luz ese mismo año bajo el título Atrapados en la ratonera. Memorias de una novelista (Medio, 1980). En ella, en efecto, la autora cita con profusión a Cabezas, y en concreto su obra Asturias: catorce meses de guerra civil (Medio 1980, 36, 39, 44-45, 83, 87, 124-125, 130, 135-136, 138-139, 186-187).

La misiva del escritor asturiano Manuel Pilares (1921-1992), sin fecha, podría datar del año 1984, cuando apareció el libro de Cabezas por el que Pilares le felicita. Se trata de la reedición de Héroe de paz (Cabezas 1984a), una obra que Cabezas escribió en 1943, mientras cumplía pena de prisión en la cárcel de Porlier de Madrid, y que vio la luz en 1946.

Por último, la carta de Natalia Figueroa aparece fechada un 25 de abril en Key Biscayne (Florida, EE. UU.), y con seguridad se refiere al año 1990, pues en sus breves palabras agradece a Cabezas un reportaje sobre su familia en Época. El trabajo lleva por título «Los Romanones» (Cabezas 1990), y forma parte de una serie que el periodista dedicó a grandes familias españolas. En él se traza el perfil profesional y familiar de Natalia Figueroa, nieta del conde de Romanones e hija de Agustín de Figueroa y de María Gamboa, marqueses de Santo Floro. Además, Juan Antonio Cabezas relata algunos momentos significativos de la vida política de Romanones, y va deteniéndose a continuación en sus descendientes. 


\section{LA EDICIÓN}

Para llevar a cabo la edición de los documentos se han examinado los originales y se ha dejado constancia de sus características más relevantes. Las cartas han sido transcritas a partir de las fotocopias realizadas de las mismas, y las intervenciones llevadas a cabo se presentan entre corchetes y en letra cursiva.

He optado por actualizar la ortografía de las cartas de acuerdo con las pautas actuales de la Real Academia Española, salvo que se trate de algún rasgo personal que sea conveniente respetar, y he corregido las erratas. En cuanto a los títulos de libros y de poemas, he preferido ceñirme al modo en que aparecen en los documentos, de ahí que algunos estén entrecomillados y otros no -salvo que el título aparezca subrayado en la carta, pues en ese caso se ofrece aquí en cursiva-.

Al texto de cada una de las cartas le he antepuesto la descripción de la misma, entre corchetes y con letra cursiva, ofreciendo además en letra redonda el texto de los membretes. En lo que respecta a las fechas, he optado por ubicarlas en el ángulo superior derecho de la página. En los casos de aquellas cartas que no están fechadas, o cuya fecha es incompleta, ofrezco entre corchetes la más probable, explicando en la nota correspondiente las razones que me llevan a esa conclusión. Las anotaciones que no forman parte del cuerpo principal del texto se transcriben al final del mismo. Por el contrario, las correcciones realizadas a mano en los documentos se incluyen entre corchetes.

\section{AgradeCIMIEnTos}

Son objeto de mi agradecimiento más profundo Julia Rosa García (q. e. p. d.), Julia Cabezas García y Elvira Bobo Cabezas, viuda, hija y nieta de Juan Antonio Cabezas, respectivamente. Sin su colaboración desinteresada no habría podido elaborarse el presente trabajo. Debo agradecer además las indicaciones de Julio Neira, catedrático de la UNED, y la ayuda de María Martínez-Cachero Rojo, profesora titular de la Universidad de Oviedo, que me orientó en la elección de estos documentos como objeto de la investigación y me facilitó el contacto con la familia Cabezas. Para profundizar en las distintas referencias que aparecen en las cartas han sido fundamentales las aportaciones puntuales y siempre reveladoras de M. ${ }^{a}$ Cristina Alas Rodríguez (q. e. p. d.) -hija de Leopoldo Alas Argüelles y nieta de Leopoldo Alas «Clarín»-, José Bueno Ramírez de Verger -hijo del periodista Javier Bueno-, Juan Cueto Alas (q. e. p. d.), Jorge Domingo Cuadriello, Pelayo Muñoz Duarte y Mirta Núñez DíazBalart, profesora de la Universidad Complutense de Madrid. 
[Carta de Ramón Gómez de la Serna. Cuartilla de color azul. Papel con membrete: [tinta negra: RAMÓN] GÓMEZ DE LA SERNA / HIPÓLITO YRIGOYEN 1974 / 6 PISO LL / TEL. 47 - 4775 (DESPUÉS DE LAS 3 DE LA TARDE) / BUENOS AIRES]

Bs As [Buenos Aires] 22 julio 1957

Mi querido y admirado amigo Cabezas: He tenido escrito el sobre de esta carta desde hace tiempo porque me seguían llegando recortes de su hermoso artículo.

Renovó como una vieja amistad, que no estaba dormida, esa evocación completa de mi vida personal y literaria. Muy bien sus apreciaciones y sus datos.

También me calmó el deseo de escribirle el que me sentí ya dentro y a su lado en la magnífica agencia de Meliá.

A Maruja Mallo ${ }^{4}$ la entregué su correspondiente recorte y le está muy agradecida.

¿Que vivamos muchos años, que articuleemos mucho y que sea por lo menos fértiles en dólares nuestra vieja e incesante labor!

Con mucha gratitud le abraza su devoto

RAMÓN

[Carta de Antonio Ortega ${ }^{5}$. Fechada el 5 de junio de 1958. Mecanografiada, con firma autógrafa. Membrete: El Director de Carteles]

Sr. Don Juan Antonio Cabezas/ Madrid

Mi querido Juan Antonio:

Hace tanto tiempo que no sé de ti directamente que ya me he olvidado de si eres tú el que me debes carta a mí o soy yo el que te la debo a ti. Pero esto importa poco. Bástate con saber que te recuerdo con cariño y que te leo con admiración. (He leído y tengo en mi biblioteca tu «Madrid» ${ }^{6}$ y tu «Asturias $\left.{ }^{7} »\right)$. Por otra parte, escribirte después de veinte años de ausencia no tendría sentido. Cuando el exilio se hace muy largo se recuerdan cosas que nunca han existido porque han pasado para siempre, mientras nosotros seguimos todavía aquí con una vida distinta, aún no gastada, en nuestras manos... No, después de tantos años, no hay diálogo posible a través de una carta; serían necesarios varios días para hablar,

${ }^{4}$ La pintora se exilió en Buenos Aires en 1937, y regresó definitivamente a España en 1965. El propio Gómez de la Serna escribió un breve acercamiento biográfico a Maruja Mallo, que sirvió como introducción a una obra con grabados y láminas de la artista (Mallo 1942).

${ }^{5} \mathrm{La}$ amistad entre Juan Antonio Cabezas (en adelante, JAC) y Antonio Ortega venía ya de los años en que el primero dirigía El Carbayón (1928-1931) y el segundo ejercía como profesor y más tarde catedrático de instituto en Oviedo, y en 1932 director de Avance (cfr. Cabezas García 2018a). Julia Cabezas García señala que «al estallar la guerra es cuando los dos se trasladan al Gijón revolucionario, JAC a seguir con su oficio de periodista en Avance de Gijón (que empezó a publicarse los primeros días de enero de 1937) y Ortega para ponerse al servicio de su partido, desde el que llegó a tener el Departamento de Propaganda. Ambos asistían a las tertulias del atardecer, junto con Javier Bueno, Vega Pico, Ovidio Gondi... en el incautado edificio de El Comercio» (Cabezas García 2018a).

${ }^{6}$ Libro de JAC (Cabezas 1954) que aborda aspectos relacionados con la historia de los monumentos artísticos de Madrid.

7 Se refiere a Asturias: biografía de una región (Cabezas 1956). 
con muchas botellas de sidra por delante y algún que otro centollo sobre la mesa... Pero en fin, confiemos en que todavía nos quede cuerda suficiente para que lleguemos a vernos ${ }^{8}$ cualquier día en cualquier sitio y entonces poner en orden nuestros recuerdos comunes, rumiar las alegrías pasadas y enterrar definitivamente a nuestros muertos.

Mientras ese día llega te presento a mi buen amigo y compañero Mario Díaz Aguirre $^{9}$, portador de estas líneas. Mario es un gran escritor y periodista. Colabora conmigo en Carteles. Va a España por esa oscura necesidad que sienten muchos buenos cubanos de comprobar que ahí hay algo más que «gallegos» de profuso bigote y excelentes embutidos. Va también a editar un libro, sus «Cromos de Ayer ${ }^{10}$, la mayor parte de los cuales han visto la luz pública en «Carteles» ${ }^{11}$.

Deseo que lo atiendas, que le presentes a los buenos amigos que por ahí me queden, que le facilites las gestiones que tendrá que hacer para sacar su libro... Deseo también que le enseñes la otra cara de España que está por debajo de los «luceros», los «yugos» y la «vocación de imperio» actuales. Esa otra cara de España que es preciso mostrar a los americanos para que nos perdonen el haber descubierto América y se descubran a sí mismos. Tú, asturiano de mente clara que has vivido en América ${ }^{12}$, sé que aceptarás mi encargo. Puedo decirte también que todo lo que hagas por Mario Díaz Aguirre se lo merece.

Y nada más por hoy. Pese a mi úlcera -ya no de duodeno sino de yeyunoconfío todavía en poder dialogar contigo platónicamente en una de esas universidades populares asturianas que son los chigres $^{13}$, e incluso sumar nuestras voces -ya la sidra un poco cocorota- en un corín más o menos desafinado, rememorando el campo de San Roque, «donde las ligas se pierden», o a la molinera que tiene collares «que non salen del molín» ${ }^{14}$, y en cuya reputación tanto se ha cebado la malignidad astur. [...]

Un abrazo muy fuerte de,

[Añadido a mano: Apartado 188 La Habana]

Antonio Ortega

Junio 5, 1958

[Carta de Mariano Sánchez Roca. Mecanografiada, con firma autógrafa. Papel con membrete: MARIANO SÁNCHEZ ROCA / ABOGADO]

Sr. Don Juan Antonio Cabezas

Reina Victoria, 42

Madrid

San Juan de Luz, 9 de diciembre de 1961

${ }^{8}$ Ortega se había exiliado en Cuba y posteriormente en Venezuela, donde falleció en 1970. El reencuentro entre ambos no llegó a producirse (cfr. Cabezas García 2018a).

${ }_{9}$ Periodista cubano, nacido en 1900. Trabajó en varios periódicos de la isla y obtuvo los premios Enrique José Varona y Juan Gualberto Gómez.

${ }^{10}$ No tengo constancia de que Cromos de ayer llegara a publicarse.

11 Revista cubana de carácter popular, fundada en 1919 y clausurada en 1960.

12 JAC emigró a Cuba a los dieciséis años, donde vivió hasta los veinticinco.

${ }_{13}$ En asturiano, establecimiento en el que se sirven bebidas.

14 Referencia a dos canciones tradicionales. 
Querido Juan Antonio:

Su afectuosa carta también me ha producido a mí gran impresión, no solo por las evocaciones que ella conlleva, sino porque es la primera que proveniente de nuestro país me da la sensación de que a pesar de no haberse restablecido todavía, al cabo de más de un cuarto de siglo, el equilibrio moral entre los españoles, demuestra que las amistades que eran verdaderas subsisten con aquellos matices de cariño que son tan indispensables en la vida como cualesquiera otra cosa muy esencial.

Lamento mucho lo que me dice de su imposibilidad de venir; vamos a ver si puedo ser yo el que vaya a verle, pues no le niego que la nostalgia fue mi inseparable compañera durante muchos años respecto a España, y que cuando las circunstancias de orden político me obligaron a salir de Cuba ${ }^{15}$, mi inclinación tendía hacia mi pueblo y la brújula que marcaba nuestro rumbo apuntaba hacia mi Madrid. Después, algunas peripecias intranscendentes pero mortificantes me confirmaron que aquello que a mí me parecía relativamente sencillo, como consecuencia, además, de actos del Poder, no lo era, sino que estaba latente, hipócritamente al menos, una prevención que no olvidaba y una superioridad cívica o de ciudadanía que resultaba intolerable.

Con todo, desde el ángulo sentimental y desde el triángulo económico, mi solución, antes de morir es España. Sentimentalmente por vivir con mis hijos, el encanto de mi nieta y el afecto y cuidado de Joaquín [Maurín $]^{16}$ que ha convivido con nosotros casi treinta años y que es parte integral de la familia; y desde el triángulo económico, como en Cuba el comunismo me despojó de todos nuestros bienes, pues cuando nos asilamos en la Embajada de Venezuela no teníamos más que lo puesto, hemos recalado en Francia un tanto a la aventura, sin medios apenas para subsistir una breve temporada, sin posibilidades de obtener ingreso alguno, pues yo aquí no tengo nada que hacer como no sea incomodarme con el panorama del Mundo, pasar rabietas cada día con lo que leo y afianzar el convencimiento de que el número de los cretinos se multiplica diariamente en proporción considerable. Así pues estoy decidido a ir al Consulado español de Hendaya, rellenar unos Formularios despreciando aquello que suponga humillación y solicitar la vuelta a España. Me alegra saber que Gonzalito ${ }^{17}$, de cuyo afecto también yo estoy seguro, podrá ayudar la gestión. En definitiva lo que yo voy a pedir es morir en mi pueblo, pues la verdad me molestaría mucho quedarme por estas latitudes ${ }^{18}$.

15 Sánchez Roca había abandonado Cuba ese mismo año por sus discrepancias con el castrismo, y se había establecido en Francia.

16 Joaquín Maurín Juliá fue director de la American Literary Agency de Nueva York, para la que JAC escribió artículos entre 1954 y 1988 (al comienzo cuatro mensuales, cifra que se redujo a dos con el paso de los años). Estos se distribuían a distintos periódicos americanos, como son los casos de Diario de Nueva York, El Universal de Caracas, Diario Las Américas de Miami, El Porvenir de México, La Estrella de Panamá y El Diario de Hoy de El Salvador.

${ }^{17}$ Es posible que se refiera a Gonzalo P. Delgrás (1897-1984), director de cine nacido en Barcelona y muy vinculado a Asturias. Llevó a la gran pantalla la novela de Concha Espina Altar mayor, con Cangas de Onís como escenario. Fue esposo de la actriz Margarita Robles.

${ }^{18} \mathrm{El}$ autor vio su deseo cumplido y pudo regresar a Madrid, donde falleció en agosto de 1967. 
Ya sabe pues, de dos cosas esenciales, una. La otra es lo relativo a mi libro. En síntesis le diré que es un libro que a todos los presuntos editores les parece excesivamente fuerte. Usted conoce bien mi carácter y sabe que mi norma en la vida fue no casarme con nadie más que con mi mujer. A los gringos les doy «lo suyo», pues incuestionablemente son los directos responsables no solo de toda la tragedia de Cuba y de que el comunismo haya sentado plaza a noventa millas de sus costas, sino de que el marxismo, al estímulo de la existencia de más de cuarenta millones de parias que existen en América, donde el hambre es cierta, la injusticia social manifiesta y la codicia y rapiña de los capitalistas evidente, ofrezca un campo de acción ilimitado, para cuyo aliento basta con sustituir miserias por doctrina. $\mathrm{La}$ edición en Francia es posible a través de René Julliard ${ }^{19}$; pero en Londres me falló porque dicen que los problemas americanos deben ser resueltos por los del Norte y que a ellos lo único que les interesa son las cuestiones del Lejano y Medio Oriente. En la edición en español yo tengo gran entusiasmo porque tengo la seguridad de que remitidos los ejemplares a Miami, donde hay más de 150.000 exiliados y casi 100.000 residentes anticastristas, la venta de la obra podía ser un gran éxito no sólo político sino económico ${ }^{20}$. Desde luego algunas ediciones de carácter político he visto hechas en Barcelona por distintas editoriales. Para facilitar su posible gestión, le envío con Joaquín una copia de la obra, para que usted la lea y le pueda servir de base para posible acción. Y en el caso de que no pueda ser, pues me la devuelve y mala suerte, pues tengo a la cristiandad tan vuelta de espaldas que nada que me pueda ser propicio se produce. Acaso como Joaquín le explicará agrupando ayudas financieras de amigos podamos llegar pronto a montar una buena imprenta en Madrid, que podría tener éxito prestando especial atención al libro. Un factor importante que no ignoro es el de la censura, pero ahí no habría ningún inconveniente pues el anticomunismo rezuma en las páginas y no hay la menor alusión para intervenir el lápiz rojo. Si lo de la imprenta resultase, ya se pondría usted de acuerdo con Joaquín por si pudiese ayudarle en las gestiones a realizar.

Y nada más, querido Juan Antonio. Gracias de nuevo por su carta. Hágale a Gonzalito expresivo recuerdo mío, pues a mí me parecen de ayer los días que nos reuníamos en la calle Uría para orientar la opinión... Deseo que su hijo esté mejor y repuesto. Y con saludos nuestros para usted y su esposa, le abraza con mucho afecto su antiguo y buen amigo

M. Sánchez Roca

[Carta de Dionisio Gamallo. Mecanografiada, con firma autógrafa]

Oviedo, 27 de marzo de 1963

\section{Sr. D. Juan Antonio Cabezas}

Mi querido y admirado amigo: aunque es más que probable que ya lo sepas te comunico lo que me dice mi pariente y amigo Victoriano López, secretario técnico del Instituto Nacional de Cinematografía:

19 El editor francés René Julliard (1900-1962) fundó en los años 30 Editions Julliard, que hoy pertenece al grupo Robert Laffont.

${ }^{20}$ No he encontrado constancia de que Sánchez Roca llegara a publicar la obra a la que se refiere. 
«Con relación al documental "ASÍ ES ASTURIAS"21, de Juan Antonio Cabezas, se le ha concedido una subvención de 285.000 pesetas, equivalente al 30 por ciento $\left(2^{\mathrm{a}} \mathrm{A}\right)$ de un vote de 950.000 pesetas».

Ignoro si os han tratado bien o no, porque no soy experto en esos porcentajes, ni sé lo que habitualmente se concede, y me limito a reproducir lo que me dicen.

El pasado mes he adquirido la propiedad material [añadido a mano: y un tercio de la intelectual, hasta que desquite los 6.000 duros] del Epistolario a «Clarín»: 715 cartas, que redondean mi conocimiento de tu «héroe» ${ }^{22}$. Naturalmente que renuncio a comerciar con ellas y aunque se me brindan oportunidades de multiplicar las 30.000 pesetas que pagué, en honor a la memoria de Leopoldo Alas me limitaré a utilizarlas literariamente (y si se publican compactamente, en tomos, percibirán derechos los legítimos herederos del gran escritor) y el día que haya aquí en Oviedo, o en Madrid, un organismo cultural encariñado con la fama de Leopoldo Alas, o se organice un museo dedicado al culto de su memoria, dispuesto estaré a aportar dicho tesoro epistolar, riquísima colección de autógrafos ilustres, con la única exigencia por mi parte de que no se dispersen, [añadido a mano: o] se mutilen, o parcialmente destruyan, porque cartas hay que determinadas gentes desearían no se hubieran escrito nunca, ya que sirven para comprobar que el tradicional sectarismo español ha ido en muchos aspectos «in crescendo» y que altos espíritus como Pereda, M. Pelayo, Maura, etcétera, trataron a Alas con bastante más generosidad y justicia que carcas de tercera y cuarta categoría de ahora.

Por todo ello, me permito creer que el epistolario ha venido a caer a buenas maneras, y que «Clarín», y los que con él se correspondieron, han tenido suerte. ¡Y que Dios me perdone la inmodestia...!

Sin más por hoy, te abraza afectuosament[añadido a mano: e] tu siempre buen amigo

Dionisio Gamallo

[Carta de José M. ${ }^{a}$ Pemán. Mecanografiada, con firma autógrafa]

Cádiz, 15-4-67

Sr. D. Juan A. Cabezas

MADRID

Mi querido y admirado amigo:

Enhorabuena por su «Cervantes del mito al hombre» ${ }^{23}$. Estoy avanzado en su lectura y lo encuentro lleno de sugestión y novedades.

Un cordial saludo:

José Ma Pemán

${ }^{21}$ JAC fue el guionista y director de este documental, de 63 minutos de duración, que se estrenó el 21 de octubre de 1963 en el Cine Rex de Madrid. En él se lleva a cabo una aproximación al paisaje de la región, la importancia de la minería y la industria, el folclore, así como a las fiestas más emblemáticas.

${ }^{22}$ El hecho de haber escrito la primera biografía de Leopoldo Alas propicia que se subraye así la admiración de JAC por el autor de La Regenta.

${ }^{23}$ Cabezas 1967. 
[Carta de José M. ${ }^{a}$ de Cossío. Mecanografiada, con firma autógrafa]

Tudanca 12 de julio de 1967

Sr. D. Juan A. Cabezas

Mi querido amigo: recibo su carta y en realidad poco podría decirle que interesara a nadie de mi fugaz contacto con Rubén Darío ${ }^{24}$ en Madrid a su paso durante el tiempo que pasó en Valdemosa, con los Suredas ${ }^{25}$.

Otro extremo de su carta puede tener más cumplida realización: su anunciado viaje a la montaña. Sería para mí una satisfacción verdadera el atenderle en esta Casona ${ }^{26}$, y no le perdonaría nunca que no la visitara en su paso por la montaña ${ }^{27}$.

Tengo de usted el recuerdo diario de su colaboración en $\mathrm{ABC}$ que leo con el mayor interés siempre, y de su amabilidad nunca desmentida.

Reciba el saludo más cordial de su muy devoto y buen amigo

José $\mathrm{M}^{\mathrm{a}}$ de Cossío

\section{[Carta de Guillermo de Torre]}

Ibiza $60,6^{\circ}, \mathrm{A}$. Tel 273-5944

Madrid, 5 julio 1968

Sr. D. Juan Antonio Cabezas.

Querido compañero y antiguo amigo:

Como no sé su teléfono, como no le he encontrado nunca en $A B C$, cuando he preguntado por usted, le mando estas líneas de saludo y agradecimiento por su mención en la «Tertulia literaria» última ${ }^{28}$.

¿Sigue usted yendo al Lion, donde nos encontramos en mi último viaje, hace dos años? En ese café, o donde quiera que me cite, me será gratísimo charlar un rato con usted. Le anticipo un muy amistoso saludo

Guillermo de Torre

${ }^{24}$ La biografía que JAC publicó de Rubén Darío en 1944 obtuvo el Premio Fastenrath de la Real Academia Española al año siguiente.

${ }^{25}$ Con «los Suredas», Cossío se refiere al mecenas Juan Sureda (1873-1947) y su esposa, la pintora Pilar Montaner, en cuyo palacio se hospedó Rubén Darío en su segunda estancia en Valldemossa (Mallorca), en 1913 (la primera tuvo lugar en 1906). Aquel año la salud de Rubén ya era muy delicada, pero a pesar de ello el viaje a Valldemossa dio como fruto su novela El oro de Mallorca. Sobre la relación de Rubén con los Suredas, vid. Darío 1991, 34 y 74; Ramírez 2005, 170-187.

${ }^{26}$ La popular Casona de Tudanca, residencia de José M. a de Cossío hasta su muerte, fue construida en 1750. Allí visitaron a Cossío, entre otros, Miguel de Unamuno, Francisco Giner de los Ríos, Gerardo Diego o Gregorio Marañón.

27 JAC llegó a realizar esa visita, posiblemente en el verano de 1968.

28 «Tertulia Literaria» es el título de una sección que JAC escribía dentro del suplemento semanal «Mirador Literario», que en esa época $A B C$ publicaba cada jueves. El artículo mencionado apareció el 4 de julio de 1968, y en él JAC anuncia la cercana publicación del libro de Guillermo de Torre El espejo y el camino (Torre 1968). 
[Carta de Luis Amado-Blanco. Fechada en Roma el 9 de febrero de 1970. Mecanografiada, con firma autógrafa. Papel con membrete: EL EMBAJADOR DE CUBA ANTE LA SANTA SEDE]

Señor Don Juan Antonio Cabezas

Madrid

Querido Juan Antonio:

Tu carta me ha producido una gran tranquilidad por aquello de la duda que siempre nos asalta con nuestras cosas. Tú sabes bien, y como todos, lo que es eso. «Esteta» ${ }^{29}$ fue escrito hace unos diez años y como el tiempo con sus cambios corre que vuela, no sé, temí que se hubiera quedado atrás cubierto por el polvo del camino. Ahora veo que no. Aquello que me apuntas de su «intemporalidad» me ha llegado al alma.

Y por cierto, para que tengas completo ese mi nuevo-viejo libro Un pueblo $y$ cuatro agonías ${ }^{30}$, te estoy enviando por correo aparte la novela que te falta, «La aventada». ¿Quizás la mejor? No sé, pero yo la quiero muchísimo a pesar del tiempo que me separa de ella. Y si deseas volver sobre el libro completo, componlo ahora de esta manera: «El pueblo»; «El gato»; «Esteta Rodríguez»; «La aventada» y «Mi tío Romualdo». Ya me dirás lo que te parece en particular o en su conjunto. Te lo agradeceré de veras.

El recuerdo que me abres al hablarme de «Los hombres mueren soñando» ${ }^{31}$ (¡qué hermosísimo título!) me ha puesto la carne de gallina. Aquello de la estatua de sal al volver la cabeza, precisamente de sal, fíjate, es una verdad como un castillo. Y como yo vivo muy agitadamente, no sé si por suerte o por desgracia, cuando raramente vuelvo el ojo al camino recorrido, me estremezco de los pies a la cabeza al revivir con una potencia increíble aquellos viejos sucesos que parecían olvidados. ¿Olvidados? Ahora gracias a ti, me parece que fue ayer el viaje, los amigos, las miradas, las palabras. Dios iqué dentro está de mí todo aquello! Hace años cuando pasaba por Madrid, me reunía con Abdón — que fue mi compañero de banco en todo el bachillerato- y volvíamos siempre por la puntada. ¿Ahora? Tú me aclaras el problema: Quedamos tres. ¿Qué larga y qué corta es la vida de un hombre! Por lo menos tú y yo debemos apretarnos sobre este haz de recuerdos comunes, de lápidas comunes, de estelas comunes. Y en consecuencia voy a es-

29 Esteta Rodríguez, novela corta que forma parte del libro Un pueblo y cuatro agonías (Amado-Blanco 2003).

${ }^{30}$ Un pueblo y dos agonías (Amado-Blanco 1955). Como ya se ha mencionado, el libro está compuesto por la introducción El pueblo y por las novelas El gato y Mi tío Romualdo, mientras que posteriormente Amado-Blanco añadió Esteta Rodríguez y Mi tío Romualdo, y el título pasó a ser Un pueblo y cuatro agonías (Amado-Blanco 2003).

${ }^{31}$ Julia Cabezas recuerda que Los hombres mueren soñando era el título de una novela autobiográfica que JAC presentó en 1974 al Premio Larra, sobre memorias de la guerra civil, que patrocinaba el editor Gregorio del Toro (Cabezas García 2018b). «El editor recomendó al autor que, ya que eran relatos autobiográficos, aparecieran los nombres reales de los protagonistas. Durante los dos últimos meses de 1974, se modificaron los nombres, título, prólogo, etc. y el resultado fue el libro de memorias Asturias: catorce meses de guerra civil, con el que Cabezas obtuvo el III Premio Larra en marzo de 1975» (Cabezas García 2018b). 
cribirte a menudo para salvar nuestro ayer de la única muerte verdadera, es decir, el olvido.

Gracias por tu carta y por ese párrafo final de tu novela en el que estoy presente. Comencemos el diálogo epilogal de nuestros sueños.

Te abraza fuerte, muy fuerte

Luis Amado-Blanco

Cuando publiqué mi última novela, «Ciudad rebelde» ${ }^{32}$-que ahora está obteniendo un gran éxito aquí en Italia ${ }^{33}$ - envié dos ejemplares certificados al «ABC». Uno para el cura ${ }^{34} \mathrm{y}$ otro para ti. Tengo una media idea que el Padre la recibió pero como tú nunca me dijiste nada, temo se haya perdido. Si así fue, dímelo para enviarte un nuevo ejemplar.

Roma, 9-II-1970

[Carta de Manuel Fernández Avello. Papel con membrete: Manuel Fernández Avello / Oviedo]

[Oviedo] 4-VII-74

Querido Juan: Te devuelvo el libro y te agradezco la visita porque me ha permitido hablar de esas cosas que acompañan a uno y a uno le gusta ver que entienden los demás.

Cuando tenga el folleto sobre Bobes ${ }^{35}$ te mandaré unos ejemplos.

Un abrazo

Manolo

\section{[Carta de Jorge Guillén]}

Cambridge, Mass [Massachusetts] 18 de noviembre de 1976

Señor Don Juan Antonio Cabezas

Mi querido y admirado amigo: Me sorprendió leer aquella carta ya impresa. Me complace manifestar en público el muy sincero elogio de aquella obra. Y también celebro que pueda suscitar la aparición de algún «superviviente» de aquel deplorable momento. (Doña María Cristina Alas había sabido con gran sufrimiento muchas cosas.)

De modo que los Bueno de Florencia (Javier y Antonio) no son hijos sino ¿primos? del benemérito Javier asesinado. Gracias por esta aclaración.

A fines de este año andaré ya por Andalucía. Si me pasara por Madrid, le avisaría con el mayor gusto. (Este viaje será directo a Málaga.)

32 Amado-Blanco 1967a.

${ }_{33}^{33}$ La obra apareció en italiano bajo el título de Citta' Ribelle (Amado-Blanco 1967b).

${ }^{34}$ Se refiere al escritor y sacerdote toledano José Luis Martín Descalzo (1930-1991).

35 José Tomás Rodríguez y de la Iglesia Bobes (1782-1814), marino ovetense que fue capitán del ejército español en la guerra de la secesión de Venezuela, donde murió herido en combate. Fernández Avello publicó meses más tarde la biografía Bobes. Mariscal asturiano para la historia (Fernández Avello 1974). 
¿Cuándo publica usted su relato completo de toda aquella historia ${ }^{36}$ ? Cuente ya con mi lectura cómplice.

Muy cordialmente suyo,

Jorge Guillén

\section{[Carta de Jorge Guillén]}

Firenze 50123

Corsa Italia 28

5 de mayo de 1977

Señor Don Juan Antonio Cabezas

Madrid

Mi querido y admirado amigo:

Sentí de veras no haber dispuesto de tiempo para conversar con usted como era y es mi gran deseo. Están ya muy lejanas aquellas conversaciones de Puerto Rico $^{37}$. Habría que recordarlas. Los temas de conversación abundan...

Le escribo ahora para pedirle un favor si no es demasiado difícil llevarlo a cumplimiento. Me gustaría tener una fotocopia del artículo de don Francisco Garfias $^{38}$, «Juan Ramón y Antonio Machado» publicado en ABC, edición semanal, el 12 de mayo de 1960. ¡Casi una excavación! Es un artículo muy curioso. Estaré aquí, en Florencia, hasta el 27 de junio. (Conviene certificar la carta a Italia). ¡Infinitas gracias! Muy cordialmente suyo,

Jorge Guillén

[Carta de Dolores Medio. Mecanografiada, con firma autógrafa.]

Madrid 14 de abril de 1980

Queridos Julina ${ }^{39}$ y Juan Antonio:

Acabo de regresar de Alicante, donde estuve varios días ventilando un poco mis bronquios y mis pulmones y al llegar a casa me encontré con la gratísima sorpresa de los libros de Juan Antonio, que voy a devorar inmediatamente, con el interés con que leo todas sus obras, que me $\operatorname{prestan}^{40}$ por la vida.

Espero poder corresponderos muy pronto, enviándoos las dos obras mías que están para salir. En mis memorias ${ }^{41}$, Juan Antonio, te cito tantas veces (más que

${ }^{36}$ El relato de la Revolución de octubre de 1934, al que JAC dedicó su libro Morir en Oviedo (Cabezas 1984b).

${ }^{37}$ El encuentro al que se hace referencia tuvo lugar hacia 1969, cuando JAC cubrió como corresponsal de $A B C$ el I Congreso Hispanoamericano de Lexicografía en San Juan de Puerto Rico (Cabezas 1969, 61).

${ }^{38}$ Se refiere al poeta Francisco Garfias López (1921-2010).

39 Julia Rosa García González (1917-2020), esposa de JAC. Contrajeron matrimonio en 1943, en la cárcel de Porlier, donde el periodista cumplía pena de prisión. JAC enviudó durante la guerra civil de Julia Moro González, prima de Julia Rosa.

${ }^{40}$ En asturiano, una de las acepciones de prestar es «agradar».

${ }^{41}$ El libro apareció ese mismo año, bajo el título Atrapados en la ratonera: memorias de una novelista (Medio 1980). La segunda obra a la que hace referencia podría ser la novela El urogallo (Medio 1982). 
a ninguno de los historiadores de mi época, porque, como confieso, eres a mi juicio el mejor informado) que vamos a tener que firmar la obra a medias...

Gracias de todo corazón por este tesoro que me habéis enviado, y un abrazo muy cariñoso de vuestra vieja y leal amiga.

Dolores

[Carta de Manuel Pilares. Papel con membrete: Manuel Pilares. Sin fecha. Por su contenido parece corresponder a 1984]

[Manuel Pilares] saluda y felicita a Juan Antonio Cabezas por ese «Héroe de paz» que le ha traído una ejemplar lección de buen narrador y de bien escribir.

Querido Juan Antonio, maestro y amigo, muchas gracias. He pasado emocionantes horas con las intensas y humanísimas peripecias de tus personajes. Y he respirado el aire de nuestra Asturias. Y he oído el canto de «los tordos malvises en la sinfonía primaveral del paisaje» donde vivió tu héroe.

Ahora, en estos tiempos de renqueante transición a la democracia, vuelvo a desearte, como si estuviéramos juntos, que toda tu experiencia literaria y vital nos proporcione a cuantos hemos tenido la suerte de contar con tu amistad muchos libros más, en la seguridad de que serán recibidos con los ojos bien abiertos para ser leídos como un premio inmejorable. ¡Grandes abrazos, grandón!

Manuel Pilares

[Carta de Natalia Figueroa. Papel con membrete: Natalia Figueroa]

Key Biscayne, 25 abril $[\text { de 1990 }]^{42}$

Querido Juan Antonio:

Me ha gustado mucho la «Saga» de ÉPOCA. Compré aquí la revista con enorme ilusión! Está muy bien hecho, muy seriamente hecho. Las fotos han quedado estupendas.

Enhorabuena! Volvemos a fin de junio a Madrid.

Un fuerte abrazo!

Natalia

\section{FUENTES}

Amado-Blanco, Luis. 1955. Un pueblo y dos agonías. Atlante: México.

Amado-Blanco, Luis. 1967a. Ciudad rebelde. Barcelona: Editorial Nova Terra.

Amado-Blanco, Luis. 1967b. Citta' ribelle. Florencia: Cultura Ditrice.

Amado-Blanco, Luis. 2003. Un pueblo y cuatro agonías. Introducción y estudio de Roger González Martell. Azucel: Avilés.

Cabezas, Juan Antonio. 1932. Señorita 0-3. Madrid: Argis.

Cabezas, Juan Antonio. 1936. Clarín, el provinciano universal. Madrid: Espasa-Calpe.

Cabezas, Juan Antonio. 1942. Concepción Arenal o el sentido romántico de la justicia. Madrid: Espasa-Calpe.

Cabezas, Juan Antonio. 1944. Rubén Dario (un poeta y una vida). Madrid: Lyke.

${ }^{42}$ El año puede determinarse por la fecha del artículo mencionado en la carta (Cabezas 1990). 
Cabezas, Juan Antonio. 1946. Héroe de paz. Madrid: Saturnino Calleja.

Cabezas, Juan Antonio. 1954. Madrid. Barcelona: Destino.

Cabezas, Juan Antonio. 1956. Asturias: biografia de una región. Madrid: Espasa Calpe.

Cabezas, Juan Antonio. 1960. «Juan Ramón y Antonio Machado». Mirador literario, ABC, 12 de mayo.

Cabezas, Juan Antonio. 1962. Miguel de Cervantes. (Autor del Quijote). Plasencia: Sánchez Rodrigo.

Cabezas, Juan Antonio. 1967. Cervantes. Del mito al hombre. Madrid: Biblioteca Nueva.

Cabezas, Juan Antonio. 1968. «Tertulia literaria». Mirador literario, $A B C$, Madrid, 4 de julio.

Cabezas, Juan Antonio. 1969. «El I Congreso Hispanoamericano de Lexicografía en San Juan de Puerto Rico». $A B C, 29$ de noviembre, 61

Cabezas, Juan Antonio. 1975a. Asturias: catorce meses de guerra civil. Madrid: G. del Toro.

Cabezas, Juan Antonio. 1984a. Héroe de paz. Oviedo: EASA.

Cabezas, Juan Antonio. 1984b. Morir en Oviedo. Madrid: San Martín.

Cabezas, Juan Antonio. 1990. «Los Romanones». Época, 26 de marzo, 68-79.

Cabezas, Juan Antonio. 2010. Clarín, el provinciano universal. Prólogo de Elvira Bobo Cabezas. Oviedo: Laria.

Cabezas García, Julia. 2018a. Correspondencia con el autor de 2 de noviembre.

Cabezas García, Julia. 2018b. Correspondencia con el autor de 25 de noviembre.

Cabezas García, Julia. 2019a. Correspondencia con el autor de 15 de abril.

Fernández Avello, Manuel. 1974. Bobes. Mariscal asturiano para la historia. Oviedo: Asturex.

Gamallo Fierros, Dionisio. 1985. Dos cartas a Clarín: pésame por la muerte de su padre y reacción ante el primer tomo de «La Regenta». Oviedo: Magíster.

Gamallo Fierros, Dionisio. 1987. «La Regenta, a través de cartas inéditas de la Pardo Bazán a "Clarín"». En Clarín y La Regenta en su tiempo. Actas del Simposio Internacional, 277-312. Oviedo: Universidad.

González Martell, Roger. 2003. «Presentación». En Un pueblo y cuatro agonías, Luis Amado-Blanco, 9-26. Avilés: Azucel.

Guillén, Jorge. 1970. Guirnalda civil. Cambridge, Massachusetts: Halty Ferguson.

Medio, Dolores. 1980. Atrapados en la ratonera. Memorias de una novelista. Madrid: Alce. Medio, Dolores. 1982. El urogallo. Gijón: Noega.

Torre, Guillermo de. 1968. El espejo y el camino. Madrid: Editorial Prensa Española.

\section{BiBLIOGRAFÍA CITADA}

Bobo Cabezas, Elvira. 2010. «La biografía va por dentro». En Clarín, el provinciano universal, 7-11. Oviedo: Editorial Laria.

Botrel, Jean-François. 1997. «71 cartas de Leopoldo Alas "Clarín” a Silesio Delgado, director de Madrid Cómico, y seis de Manuel del Palacio». Boletín del Real Instituto de Estudios Asturianos LI, 149: 7-53.

Casariego, J. E. 1956. «Con "Ramón", en su torre de Buenos Aires». $A B C, 1$ de marzo de 1956, 9.

Darío, Rubén. 1991. Rubén Darío esencial. Edición de Arturo Ramoneda. Madrid: Taurus.

Díaz Cañabate, Antonio. 1978. Historia de una tertulia. Madrid: Espasa-Calpe.

Mallo, Maruja. 1942. Maruja Mallo. 59 grabados en negro y 9 láminas en color. Estudio preliminar de Ramón Gómez de la Serna. Buenos Aires: Losada. 
Menéndez Pelayo, Marcelino, Miguel de Unamuno y Armando Palacio Valdés. 1941. Epistolario. Prólogo de Gregorio Marañón. Notas de Adolfo Alas. Madrid: Escorial.

Menéndez Pelayo, Marcelino y Leopoldo Alas Clarín. 1943. Epistolario. Prólogo de Gregorio Marañón. Notas de Adolfo Alas. Madrid: Ediciones Escorial.

Ramírez, Sergio. 2005. Mil y una muertes. Madrid: Alfaguara.

Rubio Jiménez, Jesús. 2009. «Los deberes de la amistad: Clarín biógrafo de Galdós». En En buena compañía. Estudios en honor de Luciano García Lorenzo, coord. Joaquín Álvarez Barrientos, Oscar Cornago Bernal, Abraham Madroñal Durán y Carmen Menéndez Onrubia, 951-966. Madrid: CSIC.

Rubio Jiménez, Jesús. 2013. «Tres héroes emersonianos de la lengua española: Castelar, Rubén Darío y Clarín». Anales de Literatura Española Contemporánea 38 (1-2): 327-344.

Rubio Jiménez, Jesús y Antonio Deaño Gamallo. 2009. «Francisco Giner de los Ríos y Leopoldo Alas, Clarín. Nuevas cartas inéditas». Boletín de la Biblioteca de Menéndez Pelayo 85: 265-292.

Rubio Jiménez, Jesús y Antonio Deaño Gamallo. 2011. El camino de las letras. Epistolarios inéditos de Rafael Altamira y José Martínez Ruiz (Azorín), con Leopoldo Alas (Clarín). Alicante: Universidad de Alicante.

Rubio Jiménez, Jesús y Antonio Deaño Gamallo. 2012a. «45 cartas de Pereda a Clarín: a vueltas con la literatura». Boletín de la Biblioteca de Menéndez Pelayo 88 (2): 17-112.

Rubio Jiménez, Jesús y Antonio Deaño Gamallo. 2012b. «Diez cartas inéditas de Gaspar Núñez de Arce a Leopoldo Alas, Clarín: testimonios de un desencuentro». Boletín de Letras del Real Instituto de Estudios Asturianos 66: 177-204.

Rubio Jiménez, Jesús y Antonio Deaño Gamallo. 2012c. «Emilio Castelar y Leopoldo Alas, Clarín: entre la política y la literatura». Archivum 60: 9-57.

Rubio Jiménez, Jesús y Antonio Deaño Gamallo. 2013. «2 cartas inéditas de Ramón de Campoamor a Leopoldo Alas, "Clarín"». Archivum 63: 275-331.

Rubio Jiménez, Jesús y Antonio Deaño Gamallo. 2014a. «Entre París y Oviedo: 15 cartas inéditas de Enrique Gómez Carrillo a Leopoldo Alas, Clarín». Anales de Literatura Hispanoamericana 43: 129-158. https://doi.org/10.5209/rev_ALHI.2014.v43.47118

Rubio Jiménez, Jesús y Antonio Deaño Gamallo. 2014b. «Diez cartas de Adolfo Posada a Leopoldo Alas, Clarín». Cartas hispánicas 001. http://www.bibliotecalazarogaldiano.es/ carhis/001.html

Rubio Jiménez, Jesús y Antonio Deaño Gamallo. 2014c. «Vivir de la pluma: 24 cartas inéditas de Salvador Rueda y Rubén Darío a Leopoldo Alas, "Clarín"». Alicante: Biblioteca Virtual Miguel de Cervantes. http://www.cervantesvirtual.com/nd/ark:/59851/ bmcp57f5

Rubio Jiménez, Jesús y Antonio Deaño Gamallo. 2015. «Al correr de la pluma. Confidencias epistolares de Valera a Clarín». Revista de Literatura 77 (153): 249-294. https://doi. org/10.3989/revliteratura.2015.01.010

Rubio Jiménez, Jesús y Antonio Deaño Gamallo. 2018. Clarín y sus compañeros de viaje asturianos José Fernández Quevedo, Tomás Tuero y Pio Rubin: la grisura de la vida moderna. Oviedo: Ediciones de la Universidad de Oviedo.

Rubio Jiménez, Jesús y Alan E. Smith. 2005-2006. «Sesenta y seis cartas de Galdós a Clarín». Anales Galdosianos 40-41: 87-197. 